
\title{
Auditoría ambiental: responsabilidad de todos
}

Verónica Ochoa Hidalgo; Cindy Loor Mero; Kyra Ortega Parrales Universidad Laica Vicente Rocafuerte de Guayaquil

\section{Resumen}

En la actualidad la globalización ha conllevado a mejorar el área financiera y monetaria, esto ha hecho que mejoren los índices de competitividad de las organizaciones. Los cambios globales proponen concienciar de forma relevante la cultura ambiental global con el objeto de contribuir al logro de un planeta más saludable. El manejo adecuado de los instrumentos de protección ambiental, darán oportunidad a una nueva ética empresarial y responsabilidad social corporativa, dando como resultado el desarrollo sostenible y sustentable del ecosistema, donde las organizaciones buscan contribuir en pro del medio ambiente. Este proceso de concientización utiliza como recurso la auditoría ambiental, la cual propone debatir los parámetros adecuados para la contribución al medio ambiente y el normal desarrollo de las actividades empresariales, evaluando el seguimiento y cumplimiento de las medidas ambientales impartidas por los organismos respectivos, con el fin de evitar una desmesurada contaminación ambiental.

Palabras clave: Competitividad, políticas ambientales, responsabilidad social corporativa, desarrollo sostenible, auditoría ambiental.

\section{Abstract}

Today globalization has led to improved financial and monetary area, this has made to improve competitiveness indices organizations. Global changes proposed relevantly awareness of global environmental culture in order to contribute to a healthier planet. Proper management of environmental protection instruments, give opportunity for a new business ethics and corporate social responsibility, resulting in sustainable development and sustainable ecosystem, where organizations voluntarily decide to contribute to the achievement of a better society and a means cleaner environment. This process uses a resource awareness environmental audit, which proposes to discuss the appropriate parameters for contribution to the environment and the normal course of business activities, monitoring and evaluating compliance with environmental measures given by the respective agencies, in avoid an excessive pollution.

Keywords: Competitiveness, environmental policies, corporate social responsibility, sustainable development, environmental audit.

Cómo citar este artículo: Ochoa V., Loor C., y Ortega K. (2015) Auditoría ambiental: responsabilidad de todos. CUMBRES, Revista Científica. 1(2) $44-48$

\section{Cumbres}




\section{Introducción}

La competitividad de las organizaciones y el medio ambiente

En la actualidad las organizaciones se ven abocadas a manejar políticas ambientales que contribuyen con el sustento del medio ambiente, mismas que van a permitir tener mayor competitividad económica y jurídica, que se verá reflejada en el área financiera, no sólo por la optimización de los recursos sino que además de ellos, transmitirán un enfoque de sensibilidad empresarial hacia el medio ambiente. Este proceso permite elevar la eficiencia y eficacia empresarial, promoviendo el incremento del rendimiento en el equipo de trabajo, que constituye la fuerza motora de éxitos y ganancias en las organizaciones. (Sánchez, 2014)

El objetivo de este artículo es crear en las diferentes organizaciones la responsabilidad social ante el ecosistema con la que se deben manejar los diferentes recursos que están inmersos en sus procesos de producción de bienes y servicios que ofertan a los consumidores.

De acuerdo con (Flórez, 2010) los beneficios de la sensibilización empresarial ambiental son:

- Lograr la disminución de los costos ambientales y de los costos de producción de las empresas. La gestión y la optimización adecuada de los recursos naturales y de otros, reduce los consumos de energía, agua, materias primas, la generación de residuos, etc.

- Facilita la búsqueda e implementación de mejores tecnologías disponibles y tecnologías limpias, así también el reciclaje puede generar ingresos extras, y este control de desechos, uso eficiente de la energía, disposición de residuos (gastos elevados para el manejo de los desechos de materiales peligrosos) y, como beneficio adicional, mejora la calidad del producto final.

- Permitir el acceso a mercados más exigentes y restringidos por razones ambientales, diferenciándose, así, activamente con respecto a sus competidores, aumentando la actividad y efectividad de la propia empresa.

- Favorecer nuevas oportunidades y actividades empresariales, mejorando ambientalmente los productos propios o acudiendo a la producción o reutilización de otros, o acreditando al mercado bursátil y a líneas de créditos específicas.

- Mejorar la imagen general de la empresa y su credibilidad frente a clientes, consumidores, competidores, administraciones públicas y opinión pública.

- Ayudar y favorecer a las empresas en el cumplimiento de la legislación ambiental y la adopción de medidas adecuadas a las políticas ambientales correspondientes, reduciendo las reclamaciones y denuncias, con el ahorro de costes derivados correspondientes.

- Reducir los riesgos ambientales más allá del cumplimiento legal, contribuyendo, así, a la reducción de costes de la empresa

- Permitir introducir mejoras técnicas y de funcionamiento en la propia empresa, facilitando la actividad empresarial y el acceso a ciertos contratos y actividades.

- Mejorar las relaciones de las empresas con las administraciones públicas, en particular con las competentes en materia ambiental.

Las entidades constituyen agentes económicos sociales por lo que surge la necesidad de que éstas vayan sumando y adoptando actitudes y posiciones más respetuosas con el medio ambiente y los recursos naturales, que son las exigidas por las sociedades actuales a fin de prolongar la efímera salud del planeta en el que vivimos. Las organizaciones que aplican responsabilidad social empresarial son atractivas para los inversionistas por sus probabilidades de crecimiento.

\section{La auditoría ambiental como instrumento de desa- rrollo corporativo}

González, (2014) la auditoría ambiental está definida como un método encaminado a la evaluación periódica y sistemática de las operaciones realizadas por las empresas con el objetivo de detectar su situación en relación con los requerimientos de calidad ambiental.

La gestión ambiental constituye una parte integral del sistema de administrativo general de una entidad, es decir, su diseño, es un proceso continuo e interactivo. Los mecanismos y procesos para implementar políticas ambientales requieren un diseño de tareas interrelacionadas, logrando obtener el mejoramiento continuo, mismo que se verá reflejado en las actividades de la empresa como lo observamos en la figura'.

El sistema de gestión ambiental constituye una herramienta esencial para la administración empresarial ya que de ella depende el enfoque sistemático que se desprende 
Figura 1. Implementación de sistema de gestión ambiental

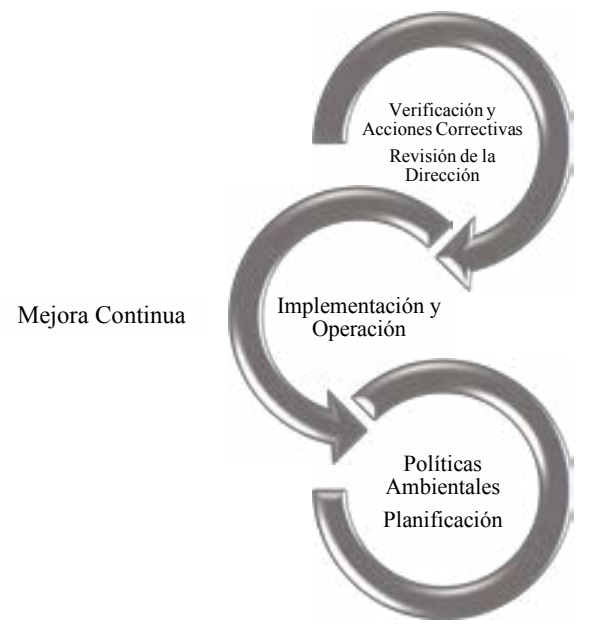

del desempeño ambiental, su establecimiento, el mismo que no sólo busca reducir el impacto ambiental adverso de forma inmediata sino que también propone crear un precedente que apertura el paso a las industrias globalizadas y demás tecnologías desarrolladas en nuestro siglo. Dentro de una organización, la auditoría ambiental debe surgir como una respuesta de visión objetiva y global que amplíe las perspectivas de los dueños y administradores mediante el manejo óptimo de los recursos naturales que permita elevar el rendimiento de los procesos, a fin de reducir las emisiones y los residuos cualquiera sea su naturaleza, o de mitigar la contaminación ambiental existente, en lo posible con ahorro de costos. Este tipo de auditoría resalta las ineficiencias del proceso y las áreas donde la administración técnica es deficiente, generando un Plan de Acción para el Manejo Ambiental.

Siendo el principal objetivo de la Auditoría Ambiental es identificar posibles deficiencias en el cumplimiento de los estándares mínimos ambientales, para así proponer e inducir a las empresas a la elaboración y ejecución de un Plan de Cumplimiento Ambiental de sistemas ecológicos, poco contaminantes, de Producción óptima de los recursos naturales, preservando el medio ambiente, y a su vez, garantizando la salud y la seguridad de la comunidad.

La auditoría ambiental actualmente es reconocida como la "ecoauditoría", "revisión ambiental", "control ambiental", "evaluación ambiental", "vigilancia ambiental", etc. Y tuvo sus principales orígenes en Estados Unidos, en donde ésta fue utilizada principalmente para identificar los impactos ambientales derivados de la actividad empresarial (Blasco y col., 2003).

La Organización Internacional de Estándares (ISO) inició en la década de los años 90 el desarrollo de un conjunto de estándares en el área de gestión ambiental, incluyendo posteriormente la auditoría ambiental basándose en las normas británicas BS 7700, las que dieron origen a las actualmente existentes Series ISO 14000.

Muchos negocios e industrias contribuyen al deterioro de nuestro entorno, reduciendo la vida de nuestro planeta. Esto no sólo perjudica al ecosistema sino a todos los seres que en él habitan y por ende a nuestra humanidad; aunque muchas de las consecuencias son reflejadas a mediano y corto plazo, los estragos de continuas administraciones indiferentes a este tema, son cada día más evidentes, lo que nos lleva a analizar de forma exhaustiva la relevancia de este tema.

La auditoría ambiental no es sólo el estudio de los factores y detecciones de procesos que deterioran el ambiente sino también la ejecución de planes de acción inmediata de parte de las organizaciones, quienes deben enfatizar su cultura y responsabilidad social, su compromiso ético con la comunidad que permita poner la vida por encima del capital, despejando cualquier duda respecto al tratamiento del entorno con el respeto que se merece.

Dentro de las cifras oficiales manejadas por el Instituto Ecuatoriano de Estadísticas y Censos (INEC) se controla el registro de los hoteles, restaurantes y demás servicios, mismos que detallamos a continuación en el Cuadro 1:

Como observamos en el Cuadro 1, se divisa las proporciones de producción de las organizaciones destinadas a prestar servicios, por ellos se infiere en la magna capacidad que poseen estas empresas y su impacto al medio ambiente como producto de la ejecución de sus actividades corporativas (Zacarías, 2013). Resulta por ende, indispensable la ejecución de auditorías ambientales que promuevan el mejoramiento continuo de los procesos y la ejecución de planes de acción conjuntamente con la comunidad en general que permita formar nuevas generaciones conscientes de que el planeta en el que viven es su hogar y que deben cuidarlo.

Por ello, es necesario que la auditoría ambiental debe generar confianza a las organizaciones sobre su gestión ambiental y el cumplimiento de la legislaciones vigentes; donde se efectué un análisis completo sobre los costos económicos y legales relacionados con la posible contaminación que se puedan generar por el incumplimiento de las normas legales establecidas y a la gestión ambiental que resulte inadecuada.

\section{$46 \quad$ Cumbres}


Cuadro 1. Encuesta anual de hoteles, restaurantes y servicios serie historia (1996 - 2010)

\begin{tabular}{|c|c|c|c|c|}
\hline Años & $\begin{array}{c}\text { Nume ro } \\
\text { Establecido }\end{array}$ & $\begin{array}{c}\text { Pers onal } \\
\text { Ocupado }\end{array}$ & Re mune raciones & Producción Total \\
\hline 1996 & 676 & 32,427 & $490,685,291$ & $2,745,711,278$ \\
\hline 1997 & 714 & 39,488 & $704,899,743$ & $4,587,294,700$ \\
\hline 1998 & 728 & 42,700 & $1,088,808,498$ & $7,359,164,129$ \\
\hline 1999 & 712 & 40,575 & $1,657,953,338$ & $13,588,214,085$ \\
\hline 2000 & 724 & 44,940 & $156,307,484$ & $1,311,773,204$ \\
\hline 2001 & 748 & 48,855 & $240,673,627$ & 1760462057 \\
\hline 2002 & 617 & 56,893 & $324,872,657$ & $2,022,004,257$ \\
\hline 2003 & 911 & 55,614 & $385,450,363$ & $2,299,064,726$ \\
\hline 2004 & 1006 & 74,355 & $431,004,180$ & $2,475,049,756$ \\
\hline 2005 & 1007 & 79,266 & $500,312,590$ & $2,860,238,502$ \\
\hline 2006 & 1021 & 85,218 & $585,000,416$ & $3,558,352,344$ \\
\hline 2007 & 1000 & 82,834 & $598,736,912$ & $3,872,211,715$ \\
\hline 2008 & 979 & 80,952 & $736,578,964$ & $4,749,621,818$ \\
\hline 2009 & 1033 & 92,710 & $937,582,034$ & $5,902,155,579$ \\
\hline 2010 & 1013 & 100,215 & $1,063,460,463$ & $6,147,495,414$ \\
\hline
\end{tabular}

Hasta el año 1999, el valor de las remuneraciones y el de la producción total está expresado en miles de sucres. A partir del año 2000 está datos se presentan en dólares por el cambio del sistema monetario al que se vio evocado nuestro país. Fuente: Instituto Nacional de Estadísticas y Censos del Ecuador (INEC)

(Ley de Gestión Ambiental, Registro Oficial No. 418 del 10 de Septiembre del 2014): establece en el artículo 28 que "Toda persona natural o jurídica tiene derecho a participar en la gestión ambiental, a través de los mecanismos que para el efecto establezca el Reglamento, entre los cuales se incluirán consultas, audiencias públicas, iniciativas, propuestas o cualquier forma de asociación entre el sector público y el privado. Se concede acción popular para denunciar a quienes violen esta garantía, sin perjuicio de la responsabilidad civil y penal por denuncias o acusaciones temerarias o maliciosas. El incumplimiento del proceso de consulta al que se refiere el artículo 88 de la Constitución Política de la República tornará inejecutable la actividad de que se trate y será causal de nulidad de los contratos respectivos."

\section{Responsabilidad social corporativa y otros conceptos}

Las organizaciones a los inicios de los años 90 han concienciado la importancia de la ética empresarial y Responsabilidad Corporativa, concibiendo nuevas tendencias de comportamiento ético en las organizaciones, ampliando cuestiones sociales y ambientales, exigiendo un comportamiento empresarial respetuoso con el medio ambiente y ecosistema, involucrando a todos los empleados que laboran en el cambio con responsabilidad social, para que el mismo tenga el éxito esperado.

El éxito de la Responsabilidad Social Corporativa es comprometerse con las obligaciones que las organizaciones mantienen con la sociedad. Aceptar esta responsabilidad social conlleva a reconocer que la organización no es un medio neutro al servicio de intereses privados, sino que es un agente económico general para mejorar su calidad de vida, cuya tendencia es lograr objetivos y metas en dichos ámbitos. (Flórez, 2010)

La Organización para la Cooperación y el Desarrollo Económico (OCDE) ha dado Directrices para las Empresas Multinacionales, en las que se potencia la contribución de tales empresas al desarrollo sostenible a fin de garantizar la coherencia entre los objetivos sociales, económicos y ambientales.

El Consejo Mundial de las Empresas para el Desarrollo Sostenible (WORLD BUSINESS COUNCIL ON SUSTAINABLE DEVELOPMENT WBCSD), maneja el concepto de responsabilidad social corporativa definiéndola como el compromiso de las empresas de contribuir al desarrollo económico sostenible, trabajando con los empleados, sus familias, la comunidad local y la sociedad en general para mejorar su calidad de vida. (Asociación para el Desarrollo Social Empresarial, 2015)

En España, la Fundación "Empresa y Sociedad" (socio de Corporate Social Responsability Europe, CSR Europe) define la Responsabilidad Social Corporativa como el trabajo de una empresa de tal forma que excede las expectativas generales que la sociedad tiene respecto a las mismas, incluyendo una serie completa de políticas, prácticas y pro- 
gramas que están integrados en todas las operaciones de la propia empresa.

La Responsabilidad Social es una responsabilidad interna, en la que se incluyen aspectos de gestión de recursos humanos, salud y seguridad en el trabajo, adaptaciones a los cambios y a la gestión del impacto ambiental y de los recursos naturales.

Se entiende que la reducción de contaminación, del consumo de recursos naturales, de la generación de residuos pueden augurar a las empresas en un incremento de la rentabilidad y competitividad; los cuales de desarrollaran a través del manejo de Programas ambientales, a través de Auditorías Ambientales.

\section{Conclusiones}

1. La sociedad exige nuestra actitud y fuerza de voluntad que promueva el desempeño de actividades libres de contaminación ambiental. Dejemos un legado de concientización social, creando vínculos con la actividad productiva, comercial y de servicio para que tengan conciencia y pongan en práctica tecnologías de punta, que ayuden a minimizar el grave daño que se le está haciendo al ecosistema.

2. Culminado este reporte investigativo concluimos que es necesario que las instituciones comerciales no solo se interesen de ganar dinero sino más bien de motivar a sus empleados y usuarios respecto al buen uso de esta tecnología que permita cuidar el planeta.

3. Es necesario que este tema sea adoptado como una política de estado de trascendencia, a fin de empezar a poner el ejemplo en los niños que reciben información diaria de cocina, mensajes, y que mediante esos instrumentos de divulgación se planteen reformas y actitudes de vida en nuestro planeta.
4. Se concluye indicando que la mayoría de las empresas están llamadas a percibir mayores ingresos, al poner en práctica la Responsabilidad Ambiental Empresarial, además de las bondades económicas y sociales que esto representa para su organización, convirtiéndola más competitiva y estable, por eso se invita a todas las organizaciones a formar parte de este grupo de compañías que manejan una Auditoria Ambiental que cuide al medio ambiente.

\section{Referencias bibliográficas}

- ASOCIACIÓN PARA EL DESARROLLO SOCIAL EMPRESARIAL. (ABRIL de 2015). Obtenido de www.adse.org.ar/ rse.php

- DE LA CUESTA, M. V. (2003). Promoción institucional de la responsabilidad social corporativa. Boletín ICE Económico.

· FLÓREZ, A. H. (Enero - Junio de 2010). La obligatoriedad del Departamento de Gestión Ambiental Empresarial y su marco normativo en Colombia. Revista Pensamiento Americano, 4, 45 -49.

- GONZÁlEZ, M. D. (2 al 5 de Septiembre de 2014). El porqué de la Responsabilidad Social Corporativa. Boletín Económico del CE N²813.

- LEY DE GESTIÓN AMBIENTAL, (Registro Oficial No. 418 del 10 de Septiembre del 2014).

- MINISTERIO DE PLANIFICACIÓN FEDERAL, I. P. (2014). Marco de Gestión Ambiental y Social. Norte Grande Hídrica.

· NIÑO CUBILLOS, J. (2006). La ética empresarial. Un compromiso . Bogota: Honrad-Adenauer-Stiftung.

· SÁNCHEZ, D. F. (15 al 21 de Noviembre de 2014). a Responsabilidad Social Corporativa en materia ambiental. Boletín ICE Económico N² 2824.

\section{$48 \quad$ Cumbres}

